\title{
Tetranucleotides as a scaffold for diporphyrin arrays $^{\star}$
}

\author{
Imenne Bouamaied ${ }^{1}$, Leslie-Anne Fendt ${ }^{1}$, Markus Wiesner ${ }^{1}$, \\ Daniel Häussinger ${ }^{1}$, Nicolas Amiot ${ }^{1}$, Sandra Thöni ${ }^{1}$, and \\ Eugen Stulz $z^{1,2, \ddagger}$
${ }^{1}$ Department of Chemistry, University of Basel, St. Johanns-Ring 19, 4056 Basel, Switzerland; ${ }^{2}$ School of Chemistry, University of Southampton, Highfield, \\ Southampton SO17 1BJ, UK
}

\begin{abstract}
The incorporation of porphyrin-substituted nucleosides into tetranucleotides using phosphoramidite chemistry on solid support is reported. Both diphenyl and tetraphenyl porphyrin nucleosides were used as building blocks. This method allows the synthesis of chiral homo- and heteroporphyrinic arrays, where the composition and thus the physical properties of the array can be modulated simply by reprogramming the DNA synthesizer. The porphyrin arrays are initially isolated in the free-base form. Remetallation to give the zinc-porphyrins can be achieved using standard procedures in solution. The UV-vis spectra of the arrays are reproducible by a superposition of the absorbance spectra of the individual porphyrins, indicating an undisturbed electronic ground state of the porphyrins in the arrays. The same is true for the steady-state emission spectra of the homoporphyrinic arrays, which are not influenced by the presence of the nucleotide strand. In the mixed porphyrin arrays, large differences in the excited-state properties compared to an equimolar mixture of the building blocks are observed by means that the emission of the diphenyl porphyrin moiety is quenched to a large extent, and the overall emission is dominated by the tetraphenyl porphyrin. The covalent connection of the porphyrins via the DNA-derived backbone therefore substantially alters the excited-state and energy-transfer properties of mixed porphyrin systems. The circular dichroism (CD) spectra show induced negative cotton effects in the region of the porphyrin B-band absorption, which is due to the attachment of the chromophores to the chiral oligonucleotide backbone. Addition of a complementary tetra-adenosine did not alter any of the spectroscopic properties, neither in chloroform nor in acetonitrile solutions. Therefore, it can be concluded that no duplex is formed, which is corroborated by ${ }^{1} \mathrm{H}$ NMR spectroscopy.
\end{abstract}

Keywords: porphyrin; modified nucleotides; phosphoramidite; heteroporphyrinic arrays; homoporphyrinic arrays; energy transfer.

\section{INTRODUCTION}

The use of materials derived from biological sources has gained attention in the past years as an alternative environmentally benign source as compared to the traditional chemical manufacturing processes. Protein aggregation, programmed DNA assembly, and biomineralization processes may lead to new

\footnotetext{
*Paper based on a presentation at the Second International Symposium on Green/Sustainable Chemistry, 10-13 January 2006, Delhi, India. Other presentations are published in this issue, pp. 1971-2050.

‡Corresponding author: Tel.: +44-(0)23 805993 69; Fax: +44-(0)23 805968 05; E-mail: est@ soton.ac.uk
} 
nanostructured materials [1]. Following these new routes, we are exploring the use of DNA as a scaffold to create multiporphyrin arrays that may have applications in molecular electronics or dye-sensitized photovoltaic cells. However, considering the diversity of approaches, it appears that using biological agents and principles to create new materials is a science that is still very much in its exploratory phase. It is clear that inspiration from nature is useful, but as we do not yet know which molecules, strategies, or principles will yield the best results, many different possibilities have to be explored. In this respect, we are still relying on the traditional chemical approaches to fully understand our new DNA-based systems. As a future approach, our concept may well be applied to the use of biologically derived building blocks and methods, e.g., based on readily available heme and polymerase chain reaction (PCR) for DNA amplification.

The synthesis of multiporphyrin arrays has advanced to the point where a very large diversity of building blocks and supramolecular complexes thereof are accessible. Major interests in these constructs are in the imitation of the antenna complex of the natural photosynthetic system [2], in enzyme mimics [3,4], and in the design and synthesis of new molecular electronic [5] and photonic [6] devices. The strategies employed to build the porphyrin arrays use either direct covalent connection [7-11], a metal-to-ligand complexation approach [12-15], or noncovalent hydrogen-bonding patterns [16-19]. Covalent connection strategies have the disadvantage that the relative composition of the overall array is rather static, meaning that the exchange of individual building blocks within the array may demand a complete redesign and resynthesis of the supramolecular array. To introduce supramolecular chirality in the arrays may also not easily be achieved.

Only very recently, DNA has become attractive as a supramolecular scaffold to produce nanoscaled entities [20-26]. The double-stranded DNA (dsDNA) has been used because of its high selectivity in recognition through base-pairing to specifically connect nanoparticles [25,27-29], in DNA chip technology and nanolithography [30], to create nanomechanical devices [22], or to construct protein arrays and nanowires [31]. In this context, the use of substituted nucleotides is a very recently emerging field of research, where the dsDNA is designed to act as a template for the creation of functional molecules [32-39]. For example, DNA strands that were post-modified with porphyrins gave access to branched assemblies [40,41]. However, to date the DNA has not been used to synthesize a multifunctional molecule, where a variety of different electronically active substituents were incorporated site-specifically into the DNA strand, especially not using porphyrins as functional entities.

On our route to the use of dsDNA as a template for multiporphyrin arrays, we have studied the utility of solid-phase DNA synthesis to create homo- and heteroporphyrinic diporphyrin arrays. Based on our synthetic methodology to porphyrin-substituted nucleosides, the phosphoramidites $\mathbf{1}$ and $\mathbf{2}$ (Scheme 1) [42,43] were used as building blocks and were successfully incorporated into the tetranucleotides $\mathbf{3}$ to $\mathbf{5}$ on solid support using an automated DNA synthesizer. This provides a new synthetic route to porphyrin arrays, where the composition of the array and thus its physical properties can be changed easily. To compare the properties of the diporphyrin arrays with the individual porphyrins (i.e., to gain insight into the influence of the nucleotide backbone), the trinucleotides $\mathbf{6}$ and $\mathbf{7}$ were prepared as well. 


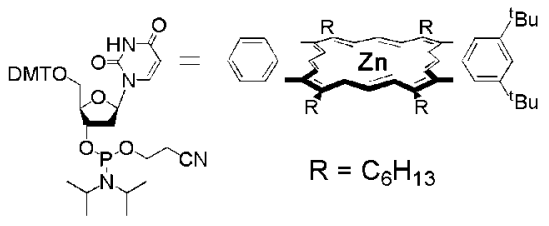

1

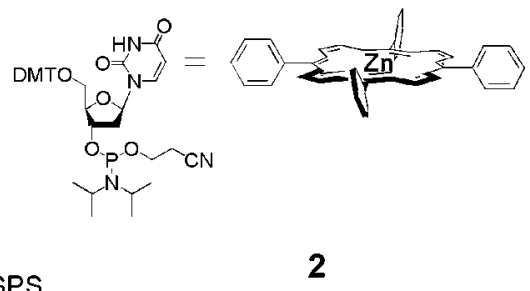

$30-45 \%$

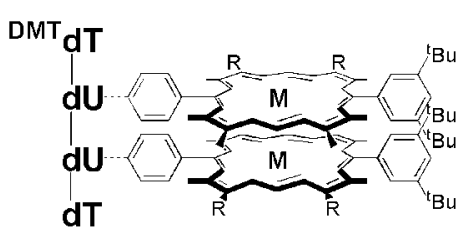

3

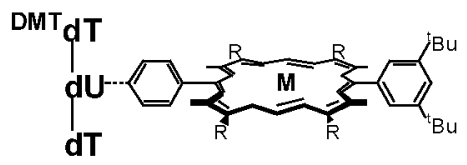

6

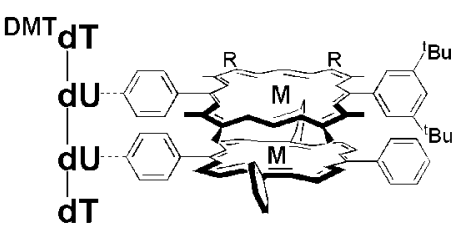

4

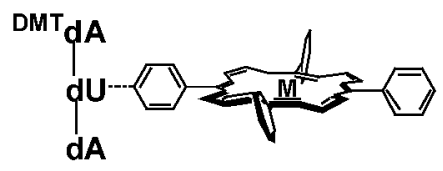

7

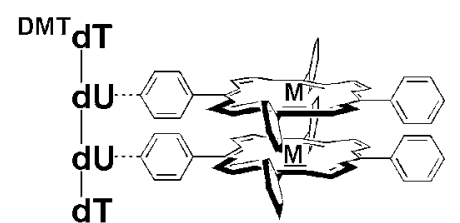

5

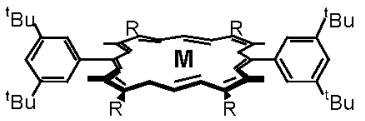

DPP 8

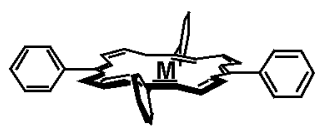

TPP 9

Scheme 1 Solid-phase synthesis of the tri- and tetranucleide porphyrin arrays. $\mathrm{M}=2 \mathrm{H}$ or $\mathrm{Zn}$. DMT = 2,2'-dimethoxy trityl; DPP = diphenyl porphyrin; TPP = tetraphenyl porphyrin.

\section{SYNTHESIS OF THE TRI- AND TETRANUCLEOTIDE PORPHYRIN ARRAYS}

The phosphoramidite building blocks 1 and $\mathbf{2}$ were obtained from the DMT-protected porphyrin nucleotides and isolated in 70 to $85 \%$ yield according to the methods described earlier $[42,43]$. Dichloromethane (DCM) solutions (20 mM) of the building blocks were prepared and used for the synthesis of the porphyrin-oligonucleotides $\mathbf{3}$ to $\mathbf{7}$ in an automated DNA synthesizer in standard mode (trityl on) on a 15- $\mu \mathrm{mol}$ scale; the coupling time for the modified building blocks was increased to $15 \mathrm{~min}$. Cleavage from the solid support was achieved with a mixture of $25 \%$ ammonium hydroxide and methanol at $40{ }^{\circ} \mathrm{C}$ over night. Due to the low solubility of $\mathbf{3}$ in this solvent mixture, a second treatment of the solid support was necessary using $25 \%$ ammonium hydroxide and dioxane $1: 1$ at $40{ }^{\circ} \mathrm{C}$ overnight. The crude products were purified on lipophilic sephadex (LH 20, DCM-MeOH 1:1). The yields of the final products as free-base porphyrins $\mathbf{H}_{2}-\mathbf{3}$ to $\mathbf{H}_{\mathbf{2}} \mathbf{- 7}$ were in the range of 30 to $45 \%$. Analysis of the products using matrix-assisted laser desorbtion/ionization time-of-flight (MALDI-TOF) mass spectrometry showed the expected $m / z$ peaks for porphyrin arrays as shown in Fig. 1 for the diporphyrins $\mathbf{H}_{\mathbf{2}}-\mathbf{3}$ to $\mathbf{H}_{\mathbf{2}} \mathbf{- 5}$. Remetallation of the porphyrin arrays to the zinc derivatives $\mathbf{Z n - 3}$ to $\mathbf{Z n - 7}$ was performed using the standard methods for porphyrin metallation with zinc acetate in DCM-methanol. Excess zinc salts were removed on lipophilic sephadex. The absorbance and emission spectra were determined using chloroform solutions of $2.5 \times 10^{-6} \mathrm{M}$ and $2.3 \times 10^{-8} \mathrm{M}$ concentration, 

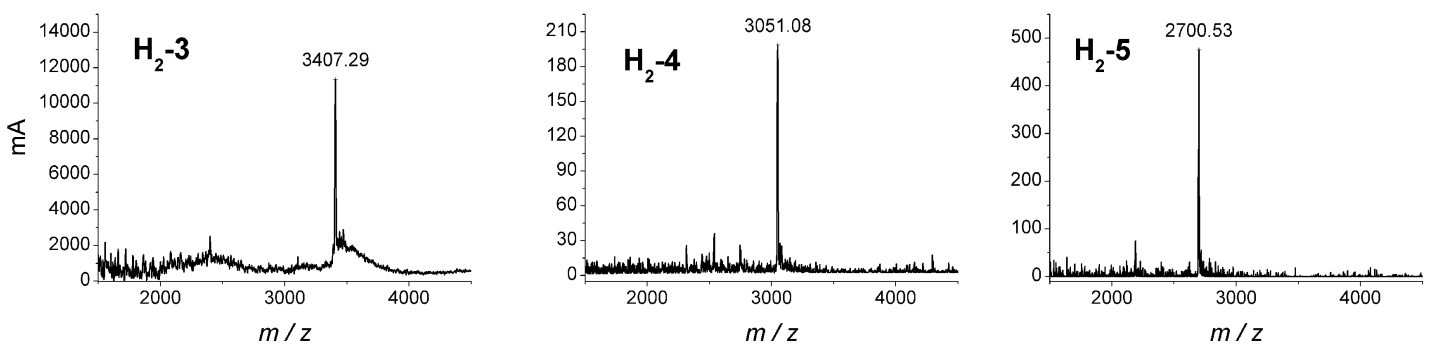

Fig. 1 MALDI-TOF mass spectra of the free-base diporphyrin arrays. Calculated values [M-1 $]^{-1}$ are 3407.13 for $\mathbf{H}_{\mathbf{2}} \mathbf{- 3}, 3054.53$ for $\mathbf{H}_{\mathbf{2}} \mathbf{- 4}$, and 2701.60 for $\mathbf{H}_{\mathbf{2}} \mathbf{- 5}$.

respectively. The concentrations used for the circular dichroism (CD) spectroscopy were variable and are indicated in Fig. 4. The ${ }^{1} \mathrm{H}$ NMR spectra were recorded either in $\mathrm{CDCl}_{3}\left(0\right.$ or $\left.10 \mathrm{mM} \mathrm{TBA}-\mathrm{PF}_{6}\right)$ or $\mathrm{CD}_{3} \mathrm{CN}$ using a $600 \mathrm{MHz}$ Bruker NMR spectrometer as $8.4 \times 10^{-4} \mathrm{M}$ solutions. All solvents were degassed and filtered through basic alumina prior to preparing the samples. All oligonucleotides were soluble under the conditions indicated, and no aggregation was observed in any experiment.

\section{UV-VIS SPECTROSCOPY}

The spectra obtained from the free-base trinucleotides 6 and 7 containing one of the porphyrins are identical to the spectra of either diphenyl porphyrin $\left(\mathrm{H}_{2} \mathrm{DPP} \mathbf{H}_{\mathbf{2}} \mathbf{- 8}\right)$ or tetraphenyl porphyrin $\left(\mathrm{H}_{2} \mathrm{TPP}\right.$ $\mathbf{H}_{2}-9$ ). The presence of the DNA backbone therefore does not influence the absorbance of the porphyrins, and no electronic interactions between the chromophores and the nucleobases occur, as was already observed in the porphyrin nucleotide building blocks [42].

In contrast to the dinucleotide-diporphyrin arrays described earlier [43], the spectra obtained from the tetranucleotides can be reproduced by a superposition of the spectra of either the individual building blocks or the trinucleotide arrays. The UV-vis absorbance spectra of the diporphyrin arrays $\mathbf{H}_{\mathbf{2}} \mathbf{- 3}$, $\mathbf{H}_{2}-\mathbf{4}$, and $\mathbf{H}_{2}-\mathbf{5}$ are shown in Fig. 2 (top). The absorbance maxima $\lambda_{\max }(\log \varepsilon)$ of the porphyrinic absorptions in the arrays are compiled in Table 1. The B-band absorbances are $411 \mathrm{~nm}$ (5.62) for $\mathbf{H}_{\mathbf{2}} \mathbf{- 3}$, $418 \mathrm{~nm}$ (5.40) for $\mathbf{H}_{\mathbf{2}} \mathbf{- 4}$, and $419 \mathrm{~nm}$ (5.72) for $\mathbf{H}_{\mathbf{2}} \mathbf{- 5}$, which are expected values for porphyrins. The four Q-band absorbances can be found in the 450 to $700 \mathrm{~nm}$ region, which is typical for free-base porphyrins. Upon addition of the complementary tetra-adenosine $\mathrm{dA}_{4}$ the absorbances remain largely unchanged apart from a small hypochromism in the array $\mathbf{H}_{2}-\mathbf{4}$ (Fig. 2). Apparently, no change in the electronic environment is induced by addition of the tetra-adenosine.

The corresponding zinc derivatives $\mathbf{Z n - 3 , ~ Z n - 4}$, and $\mathbf{Z n - 5}$ (Table 1) show maxima for the B-band absorbances, which are red-shifted only marginally in 3 , and by about $6 \mathrm{~nm}$ in $\mathbf{4}$ and 5 compared to the free-base porphyrins (the spectra are displayed in Fig. 2, bottom). This shift difference is a common value for zinc-metallated porphyrins; the values found are $413 \mathrm{~nm}$ (5.32) for $\mathbf{Z n - 3}, 424 \mathrm{~nm}$ (4.76) for $\mathbf{Z n - 4}$, and $425 \mathrm{~nm}$ (5.48) for $\mathbf{Z n - 5}$. Again, upon addition of the complementary tetra-adenosine, no significant change in the electronic spectra could be observed (data not shown). The electronic ground state of the porphyrins, therefore, is not altered when incorporated into the oligonucleotide, nor is it influenced by the absence or presence of the complementary strand. Excitonic coupling does not occur because unhindered rotation around the internucleosidic linkage seems to prevent a close contact between the porphyrin units. 

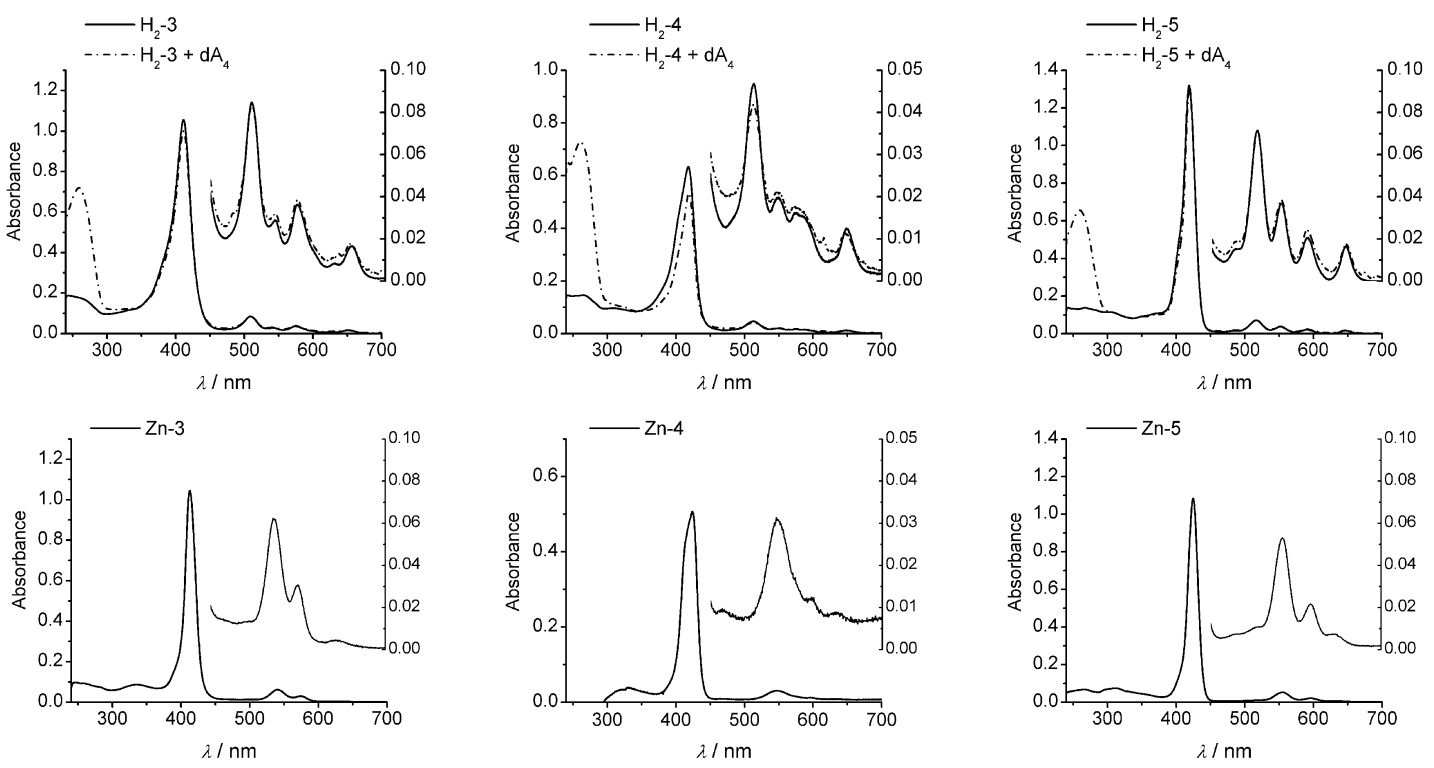

Fig. 2 UV-vis spectra of the diporphyrin arrays. The insets show the expanded Q-band region of the porphyrins.

Table 1 UV-vis absorbance data for the diporphyrin arrays 3 to $\mathbf{5}$. Data are recorded in $\mathrm{CHCl}_{3}, c=2.5 \times 10^{-6} \mathrm{M}, T=25^{\circ} \mathrm{C}$.

\begin{tabular}{lccccc}
\hline \multicolumn{3}{c}{ B-band absorption } & \multicolumn{4}{c}{ Q-band absorptions } \\
\hline $\mathbf{H}_{\mathbf{2}} \mathbf{- 3}$ & $412(5.30)$ & $510(4.21)$ & $541(3.81)$ & $576(3.88)$ & $652(3.53)$ \\
$\mathbf{Z n - 3}$ & $413(5.32)$ & & $540(4.10)$ & $574(3.78)$ & \\
$\mathbf{H}_{\mathbf{2}} \mathbf{4}$ & $418(4.75)$ & $513(3.63)$ & $544(3.49)$ & $575(3.37)$ & $648(3.20)$ \\
$\mathbf{Z n - 4}$ & $424(4.76)$ & & $545(3.13)$ & $598(3.68)$ & \\
$\mathbf{H}_{2}-\mathbf{5}$ & $419(5.38)$ & $516(4.15)$ & $553(3.96)$ & $592(3.75)$ & $646(3.63)$ \\
$\mathbf{Z n - 5}$ & $425(5.48)$ & & $555(4.08)$ & $596(3.51)$ & \\
$\mathbf{H}_{2}-\mathbf{6}$ & $417(4.79)$ & $509(3.30)$ & $544(3.43)$ & $575(3.08)$ & \\
$\mathbf{H}_{2}-\mathbf{7}$ & $418(4.86)$ & $515(3.76)$ & $552(3.57)$ & $591(3.39)$ & $645(3.28)$ \\
\hline
\end{tabular}

\section{STEADY-STATE EMISSION SPECTROSCOPY}

The steady-state emission spectra of the diporphyrin systems when irradiated at $420 \mathrm{~nm}$ show emission maxima between 600 and $750 \mathrm{~nm}$, which are characteristic for the fluorescence from the first singlet excited state S1 of porphyrins. In Fig. 3, the normalized spectra are shown for the diporphyrin arrays as well as for the individual porphyrins. There are no differences in the shape of the spectra of all the homo-porphyrin oligonucleotides when compared to the fluorescence of the model free-base porphyrins diphenyl porphyrin $\mathbf{8}$ and tetraphenyl porphyrin $\mathbf{9}$ alone or the combination of $\mathbf{8}$ and $\mathbf{9}$. Comparison with the mono-porphyrin trinucleotides shows that the presence of the DNA backbone also has no influence on the excited-state behavior of the porphyrins (data not shown). Some differences in the relative intensities of the emission bands are detectable in the zinc-metallated arrays.

The mixed porphyrin arrays $\mathbf{H}_{\mathbf{2}} \mathbf{- 4}$ and $\mathbf{Z n - 4}$, on the other hand, behave very differently compared to a mixture of the building blocks. Both the shape and the relative intensities of the normalized spectra do not correspond to a simple superposition of either the porphyrin building blocks or the trinucleotide porphyrin systems. 

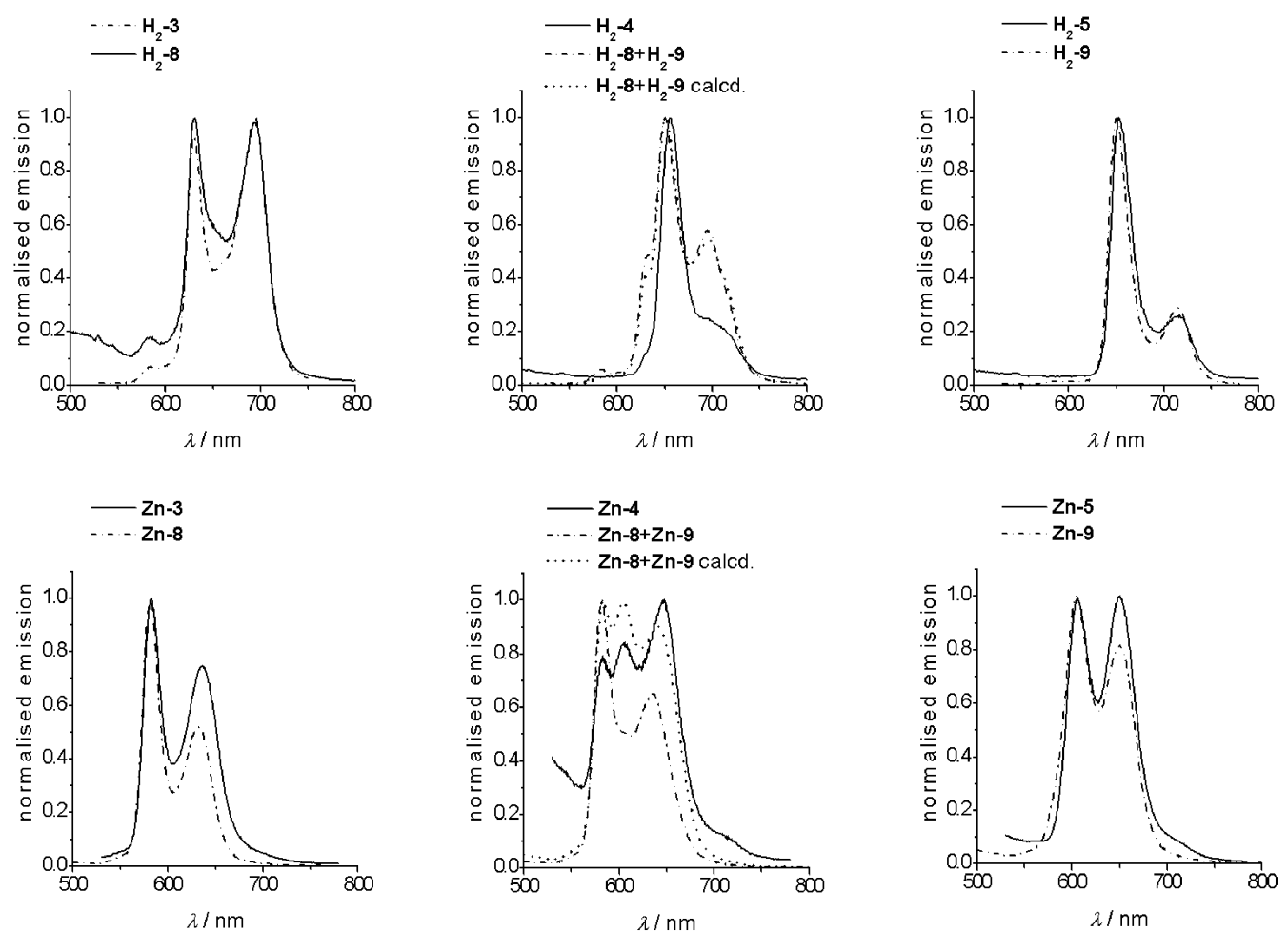

Fig. 3 Normalized steady-state emission spectra of the free-base (top) and zinc-metallated (bottom) porphyrin arrays.

In an equimolar mixture of the free-base porphyrins $\mathbf{H}_{2}-\mathbf{8}$ and $\mathbf{H}_{\mathbf{2}}-\mathbf{9}$, the spectrum corresponds well to a superposition of the emission spectra of the individual porphyrins (dash-dotted lines in Fig. 3), whereas in the case of the zinc-metallated porphyrins $\mathbf{Z n - 8}$ and $\mathbf{Z n - 9}$, the spectrum is dominated by the emission of the diphenyl porphyrin $\mathbf{Z n - 8}$. It should be noted that the relative intensity of the emission of the two porphyrins is almost equal in the free-base form, but in the zinc-metallated form, the tetraphenyl porphyrin has an emission intensity which is about $25 \%$ of that of the diphenyl porphyrin.

In $\mathbf{H}_{2}-\mathbf{4}$ and $\mathbf{Z n - 4}$, the contribution of the tetraphenyl porphyrin seems much more enhanced. In $\mathbf{H}_{\mathbf{2}}-\mathbf{4}$, the spectrum is very close in shape to the spectrum of $\mathrm{H}_{2} \mathrm{TPP}$, which indicates that the emission of the DPP part is greatly diminished. Here, also, the calculated spectrum that is obtained from the normalized spectra of $\mathbf{H}_{\mathbf{2}} \mathbf{- 8}$ and $\mathbf{H}_{\mathbf{2}}-\mathbf{9}$ represents the spectrum of the equimolar porphyrin mixture rather than of the diporphyrin array $\mathbf{H}_{\mathbf{2}} \mathbf{- 4}$. Similarly, for $\mathbf{Z n - 4}$, the emission spectrum is very different from the spectrum of an equimolar mixture of the porphyrins. The emission of the DPP porphyrin does not seem to be completely quenched, but the contribution of the TPP part is significantly enhanced. The spectrum actually is very close to the calculated spectrum obtained from the normalized emission spectra of $\mathbf{Z n - 8}$ and $\mathbf{Z n - 9}$. It can, therefore, be assumed that in the arrays an energy transfer from the DPP to the TPP part occurs, which increases the emission of the tetraphenyl porphyrin and quenches the emission of the diphenyl porphyrin. Since this effect is not detected in a mixture of the porphyrins at this low concentration, the enforced close proximity of the two chromophores through the oligonucleotide backbone leads to an intramolecular electronic communication between the porphyrins. 
Table 2 Steady-state emission data for the diporphyrin arrays 3 to 5. Data are recorded in $\mathrm{CHCl}_{3}, c=2.3 \times 10^{-8} \mathrm{M}, T=25^{\circ} \mathrm{C}$.

\begin{tabular}{llll}
\hline & & $\lambda_{\max }($ rel. intensity $)$ \\
\hline $\mathbf{H}_{\mathbf{2}} \mathbf{- 3}$ & $630(0.92)$ & $695(1)$ & \\
$\mathbf{Z n - 3}$ & $582(1)$ & $636(0.75)$ & \\
$\mathbf{H}_{\mathbf{2}}-\mathbf{4}$ & $655(1)$ & $704(\mathrm{sh})$ & \\
$\mathbf{Z n - 4}$ & $583(0.78)$ & $605(0.84)$ & \\
$\mathbf{H}_{\mathbf{2}} \mathbf{- 5}$ & $653(1)$ & $716(0.24)$ & \\
$\mathbf{Z n - 5}$ & $606(0.99)$ & $650(1)$ & \\
$\mathbf{H}_{\mathbf{2}} \mathbf{- 6}$ & $631(1)$ & $691(0.75)$ & \\
$\mathbf{Z n - 6}$ & $582(0.58)$ & $656(1)$ & \\
$\mathbf{H}_{2}-7$ & $651(1)$ & $615(0.22)$ \\
$\mathbf{Z n - 7}$ & $602(1)$ & $648(0.98)$ \\
\hline
\end{tabular}

\section{CIRCULAR DICHROISM SPECTROSCOPY}

The arrays were analyzed by CD spectroscopy in order to determine whether structural changes upon dimerization with the complementary tetra-adenosine occur. Induced CD-spectroscopy has become a valuable tool for determining changes in the helicity of oligonucleotides, and the porphyrins provide a chromophore allowing the subtle detection of changes in the supramolecular chirality [44-50]. The CD spectra of the arrays $\mathbf{H}_{2}-3$ to $\mathbf{H}_{2}-\mathbf{5}$ are shown in Fig. 4. The UV regions of the CD spectra do not show clear features, thus the spectra do not indicate highly ordered structures with respect to the oligonucleotide backbone.

Regarding the B-band region of the porphyrins, all three complexes show a similar signature in their spectra. The single-strand arrays show an induced negative cotton effect at 416, 424, and $420 \mathrm{~nm}$ for $\mathbf{H}_{\mathbf{2}}-\mathbf{3}, \mathbf{H}_{\mathbf{2}} \mathbf{- 4}$, and $\mathbf{H}_{\mathbf{2}} \mathbf{- 5}$, respectively. The values for $\lambda_{\max }$ are red-shifted by 1 to $6 \mathrm{~nm}$ compared to the B-band absorbances of the arrays. A negative cotton effect in DNA-porphyrin complexes is normally observed upon intercalation of cationic porphyrins into G-C rich sequences $[49,50]$. In the absorbance spectra, neither hypochromism nor a bathochromic shift is observed for any of the arrays as compared to the building blocks, which would be expected if strong $\pi$-interactions with the nucleobases upon intercalation would occur. The negative cotton effect can thus be explained by an induced chirality from the oligonucleotide backbone of the diporphyrin array. Noteworthy, the CD signal is strongest for the array $\mathbf{5}$, where also a sharp signal was observed. The signal of $\mathbf{3}$ is slightly broadened with a decreased intensity compared to $\mathbf{5}$. The broadest and also weakest induced signal is observed in the array 4. Upon addition of the complementary tetra-adenosine, the spectra did not change.
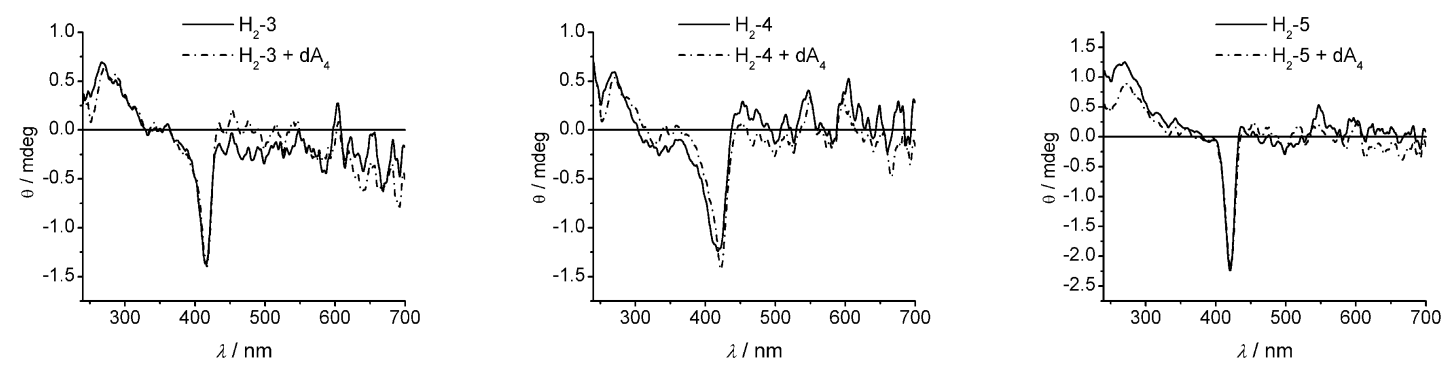

Fig. $4 \mathrm{CD}$ spectra of the free-base porphyrin arrays. Spectra are recorded in $\mathrm{CHCl}_{3}\left(T=25^{\circ} \mathrm{C}\right)$ at $c=5 \times 10^{-6} \mathrm{M}$ $\left(\mathbf{H}_{\mathbf{2}} \mathbf{- 3}\right), 13.4 \times 10^{-6} \mathrm{M}\left(\mathbf{H}_{\mathbf{2}} \mathbf{- 4}\right)$, and $3.75 \times 10^{-6} \mathrm{M}\left(\mathbf{H}_{\mathbf{2}} \mathbf{- 5}\right)$. 


\section{${ }^{1}$ H NMR SPECTROSCOPY}

It is expected that in aqueous solution, where the calculated melting point of a tetramer would be below $10{ }^{\circ} \mathrm{C}$, no duplex formation with the complementary strand takes place. This, however, does not necessarily extend to organic solutions. In chloroform, a much stronger interaction between an A-T base pair was reported, and the association constant was determined to be about $10^{2} \mathrm{M}^{-1}$ [51] which could lead to an association constant of up to $10^{8} \mathrm{M}^{-1}$ in a tetranucleotide.

In order to verify the presence or absence of any interactions between the arrays and the complementary strand, we studied the tetranucleotides by ${ }^{1} \mathrm{H}$ NMR spectroscopy. The arrays were dissolved, and the complementary strand was added until equimolar amounts were present. Either neat $\mathrm{CDCl}_{3}$ solutions or $10 \mathrm{mM}$ TBA- $\mathrm{PF}_{6}$ solutions in $\mathrm{CDCl}_{3}$ were used. However, no changes in the ${ }^{1} \mathrm{H}$ NMR spectra were observed upon addition of the complementary strand, which is shown in Fig. 5a with the array $\mathbf{H}_{2} \mathbf{- 3}$ as representative example. Further experiments were performed using both the unmodified tetrathymidine and tetra-adenosine (Figs. 5b-d). The spectrum of the equimolar mixture of $\mathrm{dT}_{4}$ and $\mathrm{dA}_{4}$ is a superposition of the individual ${ }^{1} \mathrm{H}$ NMR spectra. No changes in the resonances assigned to the sugarphosphate backbone or in the nucleobase region were seen. Also, no low-field resonances were detected at $\sim 10-15 \mathrm{ppm}$, which would be expected for the nucleobase protons when they are integrated into an A-T hydrogen-bonding system [52]. The spectra of the natural oligo-nucleotides were also measured under different conditions, e.g., in both $\mathrm{CDCl}_{3}$ and $\mathrm{CD}_{3} \mathrm{CN}$ solutions, and in the presence and absence of the noncoordinating buffer TBA-PF ${ }_{6}$, leading to the same results. Also, heating to $80{ }^{\circ} \mathrm{C}$ for $2 \mathrm{~h}$ and slow-cooling to room temperature to simulate the annealing of natural DNA did not have any influence on the outcome of the spectra. The same applies for recording the spectra at $5{ }^{\circ} \mathrm{C}$. We therefore conclude that the interactions between the two complementary tetranucleotides in organic solvents are very weak even in unmodified oligonucleotides where the steric repulsion from the bulky porphyrins is not present. 


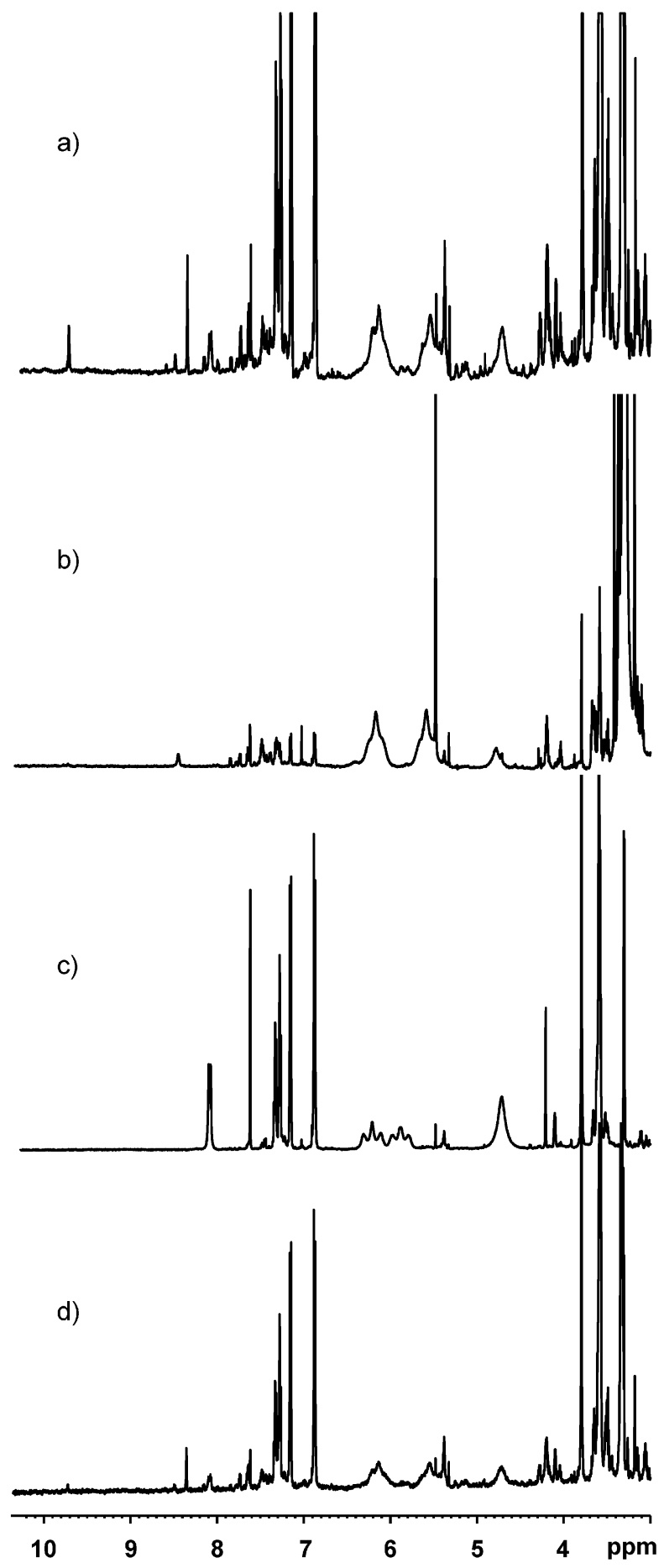

Fig. 5 Region of the ${ }^{1} \mathrm{H}$ NMR spectra of the tetranucleotides: (a) $\mathbf{H}_{2}-\mathbf{3}+\mathrm{dA}_{4}$, (b) $\mathrm{dT}_{4}$, (c) $\mathrm{dA}_{4}$, (d) $\mathrm{dT}_{4}+\mathrm{dA}_{4}$. The spectra shown are recorded in $\mathrm{CDCl}_{3}\left(10 \mathrm{mM} \mathrm{TBA}-\mathrm{PF}_{6}\right)$ for (a) and in $\mathrm{CD}_{3} \mathrm{CN}$ for (b-d). $c=8.4 \times 10^{-4} \mathrm{M}, T=$ $22{ }^{\circ} \mathrm{C}$.

(C) 2006 IUPAC, Pure and Applied Chemistry 78, 2003-2014 


\section{CONCLUSIONS}

The oligonucleotide backbone was shown to be a suitable template for the synthesis of both homo- and heteroporphyrinic diporphyrin arrays. The electronic ground-state properties of the porphyrins are largely unaffected upon incorporation into the oligonucleotide when measured in organic solvents. On the other hand, the excited state is strongly influenced by the presence or absence of a neighboring porphyrin, and electronic interactions occur depending on the structure of the adjacent porphyrin. The photophysical properties of the diporphyrin array can, therefore, be tuned simply by reprogramming the sequence of the incorporated building blocks.

There is no spectroscopic evidence for the formation of any duplex with the complementary tetraadenosine; this is also supported by the fact that the ${ }^{1} \mathrm{H}$ NMR spectra of the mixtures are represented by a superposition of the individual ${ }^{1} \mathrm{H}$ NMR spectra under very different conditions. Even though a strong interaction between the base-pairs would have been expected to occur in organic solvents, based on the reported A-T and G-C pairing in $\mathrm{CHCl}_{3}$ and DCM, this is obviously not the case in the tetranucleotides. Since the lack of interaction is already present in the unmodified nucleotides, steric hindrance arising from the bulky porphyrin units can be ruled out. To date, information on the behavior of DNA in organic solvents is very limited, but it was found that single-chain DNA undergoes compaction and thus a dramatic conformational change when the dielectric permittivity of the solvent is $<46$. The compaction of a single DNA molecule when the dielectric permittivity constant is lowered is thought to be due to the increased importance of ion-ion correlation when the electrostatic interactions are increased [53]. In our case, the dielectric permittivity is much lower ( 4.8 for $\mathrm{CHCl}_{3}$ ), therefore, electrostatic interactions become even more important. In protic solvents such as ethanol, glycerol, or ethylene glycol, the DNA duplex retains its structure though melts at a significantly lower temperature [54]. On the other hand, dimethyl sulfoxide (DMSO), methanol, and formamide did not support the duplex structure. However, these solvents are known to strongly interfere with hydrogen-bonding patterns, therefore, this cannot be directly correlated to our system where the hydrogen bondings are not expected to be disturbed. The use of noncoordinating counter-ions such as tetrabutyl ammonium or tri-ethyl ammonium may, therefore, lead to an electrostatic repulsion between the phosphate groups that prevents duplex formation. In any case, if our finding of the absence of a duplex in weakly polar aprotic solvents extends to longer DNA still needs to be shown.

We are currently probing the use of PNA as neutral complementary strand to obtain more information on possible duplex formation. Also, more detailed analyses of the excited-state electronic properties are under way to fully understand the nature of the electronic interactions between the chromophores.

\section{ACKNOWLEDGMENTS}

This work was supported by the Swiss National Science Foundation and by the Treubel-Foundation Basel, which are gratefully acknowledged.

\section{REFERENCES}

1. M. Gross. Chem. World 2, 25 (2005).

2. D. Furutsu, A. Satake, Y. Kobuke. Inorg. Chem. 44, 4460 (2005).

3. W. D. Woggon. Acc. Chem. Res. 38, 127 (2005).

4. D. M. Vriezema, M. C. Aragones, J. Elemans, J. Cornelissen, A. E. Rowan, R. J. M. Nolte. Chem. Rev. 105, 1445 (2005).

5. S. D. Straight, J. Andreasson, G. Kodis, S. Bandyopadhyay, R. H. Mitchell, T. A. Moore, A. L. Moore, D. Gust. J. Am. Chem. Soc. 127, 9403 (2005). 
6. L. Schmidt-Mende, W. M. Campbell, Q. Wang, K. W. Jolley, D. L. Officer, M. K. Nazeeruddin, M. Grätzel. ChemPhysChem 6, 1253 (2005).

7. D. Holten, D. F. Bocian, J. S. Lindsey. Acc. Chem. Res. 35, 57 (2002).

8. A. L. Kieran, S. I. Pascu, T. Jarrosson, M. J. Gunter, J. K. M. Sanders. Chem. Commun. 1842 (2005).

9. J. R. Dunetz, C. Sandstrom, E. R. Young, P. Baker, S. A. Van Name, T. Cathopolous, R. Fairman, J. C. de Paula, K. S. Akerfeldt. Org. Lett. 7, 2559 (2005).

10. M. Fujitsuka, A. Okada, S. Tojo, F. Takei, K. Onitsuka, S. Takahashi, T. Majima. J. Phys. Chem. $B$ 108, 11935 (2004).

11. M. Fujitsuka, M. Hara, S. Tojo, A. Okada, V. Troiani, N. Solladie, T. Majima. J. Phys. Chem. B 109, 33 (2005).

12. U. Michelsen, C. A. Hunter. Angew. Chem., Int. Ed. 39, 764 (2000).

13. E. Stulz, S. M. Scott, A. D. Bond, S. J. Teat, J. K. M. Sanders. Chem. Eur. J. 9, 6039 (2003).

14. E. Iengo, E. Zangrando, E. Alessio, J. C. Chambron, V. Heitz, L. Flamigni, J. P. Sauvage. Chem. Eur. J. 9, 5879 (2003).

15. I. Bouamaied, T. Coskun, E. Stulz. In Structure \& Bonding, E. Alessio (Ed.), pp. 1-48, Springer, Heidelberg (2006).

16. M. J. Gunter. In Structure \& Bonding, E. Alessio (Ed.), pp. 263-295, Springer, Heidelberg (2006).

17. V. Kral, S. L. Springs, J. L. Sessler. J. Am. Chem. Soc. 117, 8881 (1995).

18. A. Berman, E. S. Izraeli, H. Levanon, B. Wang, J. L. Sessler. J. Am. Chem. Soc. 117, 8252 (1995).

19. J. L. Sessler, B. Wang, A. Harriman. J. Am. Chem. Soc. 117, 704 (1995).

20. M. A. Batalia, E. Protozanova, R. B. MacGregor Jr., D. A. Erie. Nano Lett. 2, 269 (2002).

21. E. T. Kool. Acc. Chem. Res. 35, 936 (2002).

22. Y. Benenson, R. Adar, T. Paz-Elizur, Z. Livneh, E. Shapiro. Proc. Natl. Acad. Sci. USA 100, 2191 (2003).

23. L. H. Eckardt, K. Naumann, W. Matthias Pankau, M. Rein, M. Schweitzer, N. Windhab, G. von Kiedrowski. Nature 420, 286 (2002).

24. S. A. Davis, E. Dujardin, S. Mann. Curr. Opin. Solid State Mater. Sci. 7, 273 (2003).

25. M. Li, S. Mann. J. Mater. Chem. 14, 2260 (2004).

26. B. Giese, E. Meggers, S. Wessely, M. Spormann, A. Biland. Chimia 54, 547 (2000).

27. C. A. Mirkin. Inorg. Chem. 39, 2258 (2000).

28. M. L. Sauthier, R. L. Carroll, C. B. Gorman, S. Franzen. Langmuir 18, 1825 (2002).

29. Z. Li, R. C. Jin, C. A. Mirkin, R. L. Letsinger. Nucleic Acids Res. 30, 1558 (2002).

30. K. Keren, M. Krueger, R. Gilad, G. Ben-Yoseph, U. Sivan, E. Braun. Science 297, 72 (2002).

31. H. Yan, S. H. Park, G. Finkelstein, J. H. Reif, T. H. LaBean. Science 301, 1882 (2003).

32. O. Thum, S. Jager, M. Famulok. Angew. Chem., Int. Ed. 40, 3990 (2001).

33. T. Gourlain, A. Sidorov, N. Mignet, S. J. Thorpe, S. E. Lee, J. A. Grasby, D. M. Williams. Nucleic Acids Res. 29, 1898 (2001).

34. D. J. Hurley, Y. Tor. J. Am. Chem. Soc. 124, 3749 (2002).

35. S. I. Khan, A. E. Beilstein, G. D. Smith, M. Sykora, M. W. Grinstaff. Inorg. Chem. 38, 2411 (1999).

36. S. I. Khan, A. E. Beilstein, M. W. Grinstaff. Inorg. Chem. 38, 418 (1999).

37. K. P. Guido, H. Clever, T. Carell. Angew. Chem., Int. Ed. 44, 7204 (2005).

38. G. A. Burley, J. Gierlich, M. R. Mofid, H. Nir, S. Tal, Y. Eichen, T. Carell. J. Am. Chem. Soc. 128, 1398 (2006).

39. J. Wengel. Org. Biomol. Chem. 2, 277 (2004).

40. M. Endo, T. Shiroyama, M. Fujitsuka, T. Majima. J. Org. Chem. 70, 7468 (2005).

41. M. Endo, N. C. Seeman, T. Majima. Angew. Chem., Int. Ed. 44, 6074 (2005).

42. I. Bouamaied, E. Stulz. Synlett 1579 (2004).

43. I. Bouamaied, E. Stulz. Chimia 59, 101 (2005).

(C) 2006 IUPAC, Pure and Applied Chemistry 78, 2003-2014 
44. M. Balaz, M. De Napoli, A. E. Holmes, A. Mammana, K. Nakanishi, N. Berova, R. Purrello. Angew. Chem., Int. Ed. 44, 4006 (2005).

45. X. Huang, K. Nakanishi, N. Berova. Chirality 12, 237 (2000).

46. T. Kurtan, N. Nesnas, F. E. Koehn, Y. Q. Li, K. Nakanishi, N. Berova. J. Am. Chem. Soc. 123, $5974(2001)$

47. T. Kurtan, N. Nesnas, Y. Q. Li, X. F. Huang, K. Nakanishi, N. Berova. J. Am. Chem. Soc. 123, $5962(2001)$.

48. S. Matile, N. Berova, K. Nakanishi, J. Fleischhauer, R. W. Woody. J. Am. Chem. Soc. 118, 5198 (1996).

49. S. Lee, Y. A. Lee, H. M. Lee, J. Y. Lee, D. H. Kim, S. K. Kim. Biophys. J. 83, 371 (2002).

50. S. Lee, S. H. Jeon, B. J. Kim, S. W. Han, H. G. Jang, S. K. Kim. Biophys. Chem. 92, 35 (2001).

51. Y. Kyogoku, R. C. Lord, A. Rich. Proc. Natl. Acad. Sci. USA 57, 250 (1967).

52. K. Wüthrich. NMR of Proteins and Nucleic Acids, John Wiley, New York (1986).

53. S. M. Mel'nikov, M. O. Khan, B. Lindman, B. Jonsson. J. Am. Chem. Soc. 121, 1130 (1999).

54. G. Bonner, A. M. Klibanov. Biotechnol. Bioeng. 68, 339 (2000). 